http://jmscr.igmpublication.org/home/ ISSN (e)-2347-176x ISSN (p) 2455-0450

crossref DOI: https://dx.doi.org/10.18535/jmscr/v7i9.123

\title{
Evaluation of Pulmonary Function Tests and Nasal Symptoms Pre and Post Endoscopic Sinus Surgery in Patients with Ethmoidal Polyposis
}

\author{
Authors \\ Dr D. Sampath Rao ${ }^{1}$, Dr G. Raja Mohan, M.S. E.N.T \\ ${ }^{1}$ Assistant Professor of E.N.T, Government Medical College, Mahabubnagar \\ ${ }^{2}$ Assistant professor of E.N.T
}

\begin{abstract}
Ethmoidal polyposis (EP) is a frequent form of chronic rhinosinusitis. Medical therapy is the main modality of treatment. Non responders to medical treatment require surgical removal of polyps by Endoscopic Sinus Surgery (ESS). Many studies showed worsening of the lung function following ESS whereas few studies showed improvement in the symptoms and better quality of life. Hence this study is an attempt to assess the effect of ethmoidal polyps on the pulmonary function and also the change in the lung function in the patients with ethmoidal polyps post ESS.

Methods: A prospective observational study was conducted in a tertiary care hospital on 50 subjects with ethmoidal polyposis who were unresponsive to medical treatment and hence underwent ESS. Pulmonary function tests were assessed using spirometry and nasal symptoms were scored as per TNSS system prior to surgery and 3 months post surgery and compared with the pre op values and analysed.

Results: There were 30 males and 20 females with majority of them in the age group of 41-50 yrs. The mean pre op FVC, FEV1, MEFR were 2.94liters, 2.41 liters and 2.51 liters respectively whereas the mean post operative values were 2.95 liters, 2.39 liters and 2.49 liters respectively. The ratio of FEV1 and FVC was more than 0.7 in $98 \%$ patients pre operatively and $94 \%$ post operatively. There was no statistically significant change in lung function tests following ESS. Pre operatively majority (35) had TNSS value between 6-9 where as post operatively the score was reduced to 2-3 in many patients (38). The mean TNSS was 7.24 before surgery which declined to 2.82 after surgery with a p value $<0.0001$ indicating a statistically significant improvement in the nasal symptoms post ESS.

Conclusion: Our study shows that ESS benefits patients with nasal polyps by improving the symptoms and there by the quality of life without any adverse effects on the lower airways.

Keywords: Ethmoidal Polyps (EP), Endoscopic Sinus Surgery (ESS), Pulmonary Function Tests (PFT), Total Nasal Symptom Score (TNSS).
\end{abstract}

\section{Introduction}

Ethmoidal polyposis (EP) is a form of chronic rhino-sinusitis, always arise from the lateral wall of nose, usually from the middle meatus. Aetiology of nasal polypi is very complex and may arise in inflammatory conditions of nasal mucosa (rhinosinusitis), disorders of ciliary motility or abnormal composition of nasal mucus (cystic fibrosis). Persistence of infection causes mucosal changes, such as loss of cilia, oedema and polyp formation, thus continuing the vicious cycle in the pathology chronic rhino sinusitis ${ }^{1}$. EP cause persistent nasal obstruction, hyposmia, infection, hypoxia, hypercapnia, snoring, sleep 
disorders, increased risk of hypertension and impaired quality of $\operatorname{life}^{2}$. Various mechanisms have been proposed to explain how rhinosinusitis may affect the lower airways. Some of them are aspiration of infected sinus secretions into the lower airways during sleep, enhanced vagal stimulation in the infected sinus producing bronchospasm and excessive drying of the lower airways by mouth breathing because of nasal obstruction $^{2,3}$. Treatment of EP consists of medical therapy with intranasal steroids or a short course of systemic steroids, antibiotics, leukotriene modifiers, mast cell stabilizers and acetylsalicylic acid avoidance ${ }^{3}$. Subjects who do not respond to topical steroids require Functional Endoscopic Sinus Surgery which aims to restore normal nasal function, mucociliary clearance and promotes sinus ventilation and sinus drainage.

\section{Rationale of Study}

The benefits after surgery in relation with the pulmonary function is a debate. Certain studies like Lamblin $\mathrm{C}$ et $\mathrm{al}^{4}$ and Van der Veer et $\mathrm{al}^{5}$ reported that the patients who did not respond to medical treatment exhibited a significant decrease of FEV1 and FEV1/FVC ratio post-surgery. Whereas, studies by YoungjinAhn ${ }^{6}$ et al, and colleaguesshowed no significant change in the bronchial hyperactivity and other studies by, Gillian Dunlop et $\mathrm{al}^{7}$, Marleen Vleming ${ }^{8}$ showed improvement in the lung parameters post surgery for ethmoidal polyps. So the present study aimed at benefits of endoscopic surgery in cases of ethmoidal polyp in terms of nasal symptoms and pulmonary function in the present setting.

\section{Aims and Objectives}

The main aim of this study is to assess the pulmonary function in patients with Ethmoidal polyposis who did not respond to medical treatment and to evaluate the effect of endoscopic sinus surgery on the lung function in these patients.

\section{Material and Methods}

Study Area: Study conducted in E.N.T department, Gandhi General Hospital, Warangal, Telangana.

Study Design: This current study is comparative prospective observational, hospital based study. Time Frame: The study is conducted From DEC 2017 to NOV 2018 for a period of 1 year.

Study Population: Sample Size 50.

Inclusion Criteria: Patients of all age groups who were diagnosed endoscopically with bilateral ethmoidal polyps and who were - unresponsive to medical treatment (oral steroids for 1 week, broad spectrum antibiotics for 1-2 weeks, antihistamines for 1 month, steroid nasal spray for 1 month and saline nasal irrigation) for 1 month were subjected to ESS. Exclusion Criteria:Patients with h/o nasal surgery, pulmonary symptoms and lung pathology not attributed to allergy and asthma like COPD, pneumonia/lung abscess, ciliary dyskinesia syndromes etc. and patients lost to follow up were excluded from the study.

\section{Study Setting}

The 4 point total nasal symptom scoring (TNSS) and the pulmonary function tests which include FVC, FEV1, MEFR were done 48 hours prior to surgery and 3 months post operatively and were compared. Forced vital capacity (FVC) is the volume change of the lung between a full inspiration to total lung capacity and a maximal expiration to residual volume?

Forced expiratory volume in first second (FEV1) is the volume exhaled during the first second of a forced expiratory manoeuvre started from the level of total lung capacity. The FEV1/FVC ratio, also called Tiffeneau-Pinelli index represents the proportion of a person's vital capacity that they are able to expire in the first second. Maximum mid expiratory flow rate (MEFR) is the forced expiratory flow between $25 \%$ and $75 \%$ of the FVC (FEF25-75\%). The MEFR is also used as an index of airway obstruction ${ }^{9,10,11}$. These lung function tests are assessed by spirometry and compared with the predetermined value based on 
the patient's age, sex and BMI and the degree of derangement is calculated as mild, moderate, severe and very severe(table I $)^{9,10,11}$. TNSS is a 12-point scale derived by summing and averaging all scores for four symptoms: Rhinorrhea, nasal obstruction, sneezing, and nasal itching. Each symptom is given a score - 0 (none), 1 (mild), 2 (moderate) or 3 (severe) - resulting in a maximum recorded mean TNSS of 12 (table II). The scoring is done by the patients depending on the frequency of the symptoms and interference with daily activity. None - no symptom, mild symptom present but was not annoying or troublesome, moderate - symptom frequently troublesome but does not interfere with either routine daily activity or sleep, severe - symptom was sufficiently troublesome to have interfered with routine daily activity or sleep based on patients' assessment of severity ${ }^{12}$.

Data Collection Technique: Data was collected from the semi structured proforma sheets and spirometry charts. Data was entered in MS-excel 2007 and data was analysed using SPSS software trail version 22 . The results were assessed with a paired student $-\mathrm{T}$ test and the $\mathrm{p}$ - value was calculated for the FVC, FEV1, MEFR and TNSS (total nasal symptom scoring). $\mathrm{p}<0.05$ is considered as statistical significance.

Ethical Clearance: A clearance from the institutional ethics committee was obtained for carrying out this study. Informed consent was taken from the patients.

Conflict of Interest: There was No conflict of interest in this study. No funding or support was taken from any organization.

\section{Observations and Results}

Age \& Sex: 50 patients were taken for the study of which $60 \%$ (30) were males and $40 \%$ (20) were females. Majority were in the age group of 41-50 yrs $-32 \%$ (16) with the least being in the age group of $>60$ yrs $4 \%(2)$.

\section{Symptoms}

Pre operatively majority of patients, that is 36 had mild and moderate degree of rhinorrhea, 11 had severe rhinorrhea (total $n=47$ ) and 3 did not have the symptom at all. Post operatively 26 people did not have the symptom, 24 patients had mild and moderate degree of rhinorrhea. Whereas none of the patients had severe rhinorrhea (Table. No.1).

Pre operatively 39 patients had mild and moderate itching of the nose, 1 had severe itching (Total= 40) and 10 did not have the symptom at all. Post operatively 44 people did not have the symptom and 6 patients had mild itching. Whereas none of the patients had moderate and severe intensity of the symptom (Table. No.1).

Pre operatively 25 patients had severe blockade of nose, 24 had mild and moderate degree of nasal blockade (Total $=49$ ), only 1 patient did not have the symptom at all. Post operatively 29 patients had mild and moderate severity of the symptom, 21 patients had no symptom at all, whereas none of the patients had severe intensity of the symptom (Table. No.1).

Pre operatively 36 patients had mild and moderate intensity of sneezing, 10 had severe sneezing (Total $\mathrm{n}=46$ ), and 4 patient did not have the symptom at all. Post operatively 28 patients had mild intensity of sneezing and 22 patients had no symptom at all. Whereas none of the patients had moderate and severe intensity of the symptom (Table.No.1).

The difference between the distribution of all symptoms pre and post op were found to be statistically significant.

\section{TNSS scoring}

Preoperatively the mean symptom scoring of all the 50 patients was 7.24 and the postoperative mean score was 2.82 with a difference of 4.42 . The standard deviation was 3.017 and $\mathrm{p}$ value calculated for these mean pre and post operative total TNSS systems was $<0.0001$ which is statistically significant. 
Table.No.1 Distribution of symptoms Pre and Post operatively (ESS)

\begin{tabular}{|c|c|c|c|c|}
\hline \multicolumn{2}{|l|}{ SYMPTOMS } & PRE OP & POST OP & SIGNIFICANCE \\
\hline \multirow{2}{*}{ RHINORRHEA } & PRESENT & 47 & 24 & $p<0.00001$ \\
\hline & ABSENT & 3 & 26 & (McNemar's Test) \\
\hline \multirow{2}{*}{ ITCHING } & PRESENT & 40 & 6 & $\mathrm{p}<0.00001$ \\
\hline & ABSENT & 10 & 44 & (McNemar's Test) \\
\hline \multirow{2}{*}{ BLOCKED NOSE } & PRESENT & 49 & 29 & $p<0.00001$ \\
\hline & ABSENT & 1 & 21 & (McNemar's Test) \\
\hline \multirow{2}{*}{ SNEEZING } & PRESENT & 46 & 50 & $\mathrm{p}<0.00001$ \\
\hline & ABSENT & 4 & 0 & (McNemar's Test) \\
\hline TNSS SCORE (MEAN) & & 7.24 & 2.82 & $\begin{array}{c}\mathrm{p}<0.00001 \\
\text { (Difference between the mean) }\end{array}$ \\
\hline
\end{tabular}

\section{Pulmonary Function}

Preoperatively around 98\% (49) had mild and moderate decrease in FVC and $2 \%$ ( 1) patient had severe derangement. Post operatively, about $96 \%$ (48) of patients had mild and moderate decrease in FVC whereas $4 \%$ (2) had severe decrease in FVC(table III). The mean preoperative FVC was $2.9446 \mathrm{lit} / \mathrm{sec}$ and the mean postoperative value is $2.9562 \mathrm{lit} / \mathrm{sec}$ with a difference of -0.01160 and mean difference in standard deviation is 0.46068 . The $\mathrm{p}$ value is 0.859 (Table no.2).

Preoperatively around 96\% (48) had mild and moderate derangement of FEV1 and $4 \%$ (2) patients had severe derangement of the FEV1. Postoperatively also 96\% (48) had mild and moderate derangement of FEV1 and $4 \%$ (2) patients had severe derangement (table IV). The mean preoperative FEV1 was $2.4122 \mathrm{lit} / \mathrm{sec}$ and the mean postoperative value is $2.3918 \mathrm{lit} / \mathrm{sec}$ with a difference of 0.02040 and mean difference in standard deviation is 0.36800 . The $\mathrm{p}$ value is 0.697 (Table no.2).

Preoperatively $80 \%$ (40) had mild and moderate impairment of MEFR and $20 \%$ (10) patients had severe derangement. Postoperatively 78\% (39) had mild and moderate impairment of MEFR, 22 $\%$ (11) patients had severe derangement (table V). The mean preoperative MEFR was $2.5182 \mathrm{lit} / \mathrm{sec}$ and the mean postoperative value is $2.4988 \mathrm{lit} / \mathrm{sec}$ with a difference of 0.01940 and mean difference in standard deviation is 0.43926 . The $\mathrm{p}$ value is 0.756 (Table no.2).

The ratio of FEV1 and FVC was more than 0.7 in $98 \%$ patients pre operatively and $94 \%$ post operatively.

Table No. 2 Comparisons of Pulmonary Function Tests in Pre and Post ESS Cases

\begin{tabular}{|c|c|c|c|c|c|c|}
\hline \multirow{2}{*}{\multicolumn{2}{|c|}{$\begin{array}{l}\text { PULMONARY FUNCTION } \\
\text { TESTS }\end{array}$}} & \multicolumn{2}{|c|}{ PRE OP } & \multicolumn{2}{|c|}{ POST OP } & \multirow{2}{*}{$\begin{array}{c}\text { SIGNIFICANCE } \\
\text { (DIFFERENCE } \\
\text { BETWEEN } \\
\text { THE MEAN) }\end{array}$} \\
\hline & & NUMBER & MEAN & NUMBER & MEAN & \\
\hline \multirow[t]{2}{*}{ FVC } & $\begin{array}{ll}\text { MILD } & \text { TO } \\
\text { MAEDRATE } & \end{array}$ & 49 & \multirow{2}{*}{$\begin{array}{l}2.9446 \\
\text { lit } / \mathrm{sec}\end{array}$} & 48 & \multirow{2}{*}{$\begin{array}{l}2.9562 \\
\text { lit/sec }\end{array}$} & \multirow[t]{2}{*}{$\begin{array}{c}\mathrm{p} \text { Value } \\
0.859\end{array}$} \\
\hline & SEVERE & 1 & & 2 & & \\
\hline \multirow[t]{2}{*}{ FEV1 } & $\begin{array}{ll}\text { MILD } & \text { TO } \\
\text { MODERATE } & \end{array}$ & 48 & \multirow{2}{*}{$\begin{array}{l}2.4122 \\
\text { lit/sec }\end{array}$} & 48 & \multirow{2}{*}{$\begin{array}{l}2.3918 \\
\text { lit/sec }\end{array}$} & \multirow{2}{*}{$\begin{array}{l}\mathrm{p} \text { Value } \\
0.697\end{array}$} \\
\hline & SEVERE & 2 & & 2 & & \\
\hline \multirow[t]{2}{*}{ MEFR } & $\begin{array}{ll}\text { MILD } & \text { TO } \\
\text { MODERATE } & \end{array}$ & 40 & \multirow{2}{*}{$\begin{array}{l}2.5182 \\
\text { lit/sec }\end{array}$} & 39 & \multirow{2}{*}{$\begin{array}{l}2.4988 \\
\text { lit/sec }\end{array}$} & \multirow[t]{2}{*}{ p Value 0.756} \\
\hline & SEVERE & 10 & & 11 & & \\
\hline
\end{tabular}

\section{Discussion}

Many studies have been done previously which showed either a subjective or objective worsening/ improvement/no change in the lung functions and nasal symptoms in patients who underwent FESS for ethmoidal polyposis. But no definite 
conclusions have been made whether the surgery has any impact on the lower respiratory tract and quality of life on a long term basis. This study is an attempt to supplement data for coming to a conclusion regarding the surgical treatment of the nasal polyposis. Our study is based on objective evaluation of the lung volumes and subjective assessment of the nasal symptoms in patients with ethmoidal polyposis. 50 non- responder patients were taken into the study. The lung function tests and nasal symptoms scoring were done preoperatively and 3months post operatively, compared and analyzed.

Agee and Sex: Male predominance is seen in the present study (Male to female ratio is 1.5: 1, M$60 \%$, F-40\%) with Majority of 41-50 yrs of age group. Nearly Similar finding were seen in study done by Sridevi Karuthedath et $\mathrm{al}^{13}$ where $57 \%$ were males, $43 \%$ were females with predominant (47\%) age group of 30 to 40 years. Male predominance seen in many othe studies ${ }^{5,14,15}$

Nasal Symptomps: Post operative improvement of nasal symptoms like Rhinorrhea, itching, sneezing were significant (statistically), making the endoscopic sinus surgery, the reliable choice of treatment for ethmoidal polyposis who are not responding to medical treatment. But Vander Veer ${ }^{5}$ et al was the first investigator to report that polypectomy might aggravate asthma interms of frequency of attacks, which may not coincide with the present study findings.

Slavin et $\mathrm{al}^{16}$ in their study conducted at St. Louis University Health Sciences Centre observed that, of the patients who underwent bilateral intranasal sphenoethmoidectomy, 65\% showed significant improvement in their asthmatic state. More than $80 \%$ of the patients reported that they had experienced moderately or greatly improved nasal symptomatology, and $60 \%$ felt that asthma symptoms had improved.

Pulmonary Function: Post operatively there was no significant difference (statistically) or change in FVC, FEV1, and MEFR in the present study. However the difference in the mean pre op and post op FVC and FEV1 is 0.0116 and 0.02040 respectively the $\mathrm{p}$ value is 0.859 and 0.697 respectively, It clearly indicates that there is no worsening of parameters in the lower airways by the endoscopic sinus surgery.

Some Relavant studies have been compared with the present study in relation with pulmonary function, in Table no.3. Alexander J. Osborn et $\mathrm{al}^{14}$ study showed similar findings with the present study. Most of the other studies ${ }^{13,16,17,18}$ showed improvement postoperatively in any one parameter (FVC, FEV1, FEV1/FVC).

Table No.3 Post operative improvement of pulmonary parameters comparison with other studies

\begin{tabular}{|l|c|c|c|c|}
\hline \multirow{2}{*}{ STUDIES } & \multirow{2}{*}{ YEAR } & \multicolumn{3}{|c|}{ Post Operative } \\
\cline { 3 - 5 } & & FVC & FEV1 & FEV1/FVC \\
\hline Present Study & 2018 & No Change & No Change & No Change \\
\hline Ahmed M. Youssef, MD et al $^{16}$ & 2017 & Improved & Improved & Improved \\
\hline LIAO H et al $^{17}$ & 2015 & Improved & Improved & - \\
\hline SrideviKaruthedath et al $^{13}$ & 2014 & No Change & Improved & Improved \\
\hline PAN S et al $^{18}$ & 2014 & Improved & Improved & - \\
\hline Alexander J. Osborn et al $^{14}$ & 2011 & No Change & No Change & No Change \\
\hline Pete S Batra MD et al $^{19}$ & 2010 & - & Improved & - \\
\hline
\end{tabular}

\section{Conclusions}

This study is intended to assess the pulmonary function in patients with ethmoidal polyposis who did not respond to medical treatment and to evaluate the effect of endoscopic sinus surgery on the lung function and nasal symptoms in these patients. There is a significant clinical improvement in the nasal symptoms ( $\mathrm{p}$ value of TNSS- <0.0001) of the subjects taken into the study, post ESS and medical treatment as depicted by the TNSS system. However, there was no statistically significant change in the pulmonary function tests as all the three values FVC, FEV1, MEFR had $\mathrm{p}$ value far more than 0.05(0.859, 
$0.697,0.756$ respectively). This concludes that ESS benefits the patients with nasal polyps who did not respond to medical treatment by improving the symptoms and there by the quality of life without any adverse effects on the lower airways.

\section{Recommendation}

As this study has used plain PFT without causing any broncho-provocation via methacholine/ carbachol challenge and also a small nasal symptom scoring system- TNSS and had only limited follow up period - 3 month and small size. Hence further elaborative studies with large sample size and longer follow up periods are recommended to evaluate the effect of ESS on lower airway in nasal polyps patients.

\section{References}

1. P L Dhingra, Shruti Dhingra "Diseases of Ear, Nose and Throat \& Head and Neck Surgery" $6^{\text {th }}$ edition, New Delhi, Elsvier publication 2014,Page no.152-198.

2. Paraya Assanasen, and Robert $M$. Naclerio. Medical and surgical management of nasal polyps. Current Opinion in Otolaryngology \& Head and Neck Surgery 2001;9:27-36.

3. Scott-Brown's Otolaryngology and Head and Neck Surgey. Vol. 2; Seventh Edition

4. C Lamblin, I Tillie-Leblond, J Darras, F Dubrulle, D Chevalier, E Cardot, T Perez, B Wallaert, J J Piquet, and A B Tonnel "Sequential evaluation of pulmonary function and bronchial hyper responsiveness in patients with nasal polyposis: a prospective study." American Journal of Respiratory and Critical Care Medicine, Vol. 155, No. 1 (1997), pp. 99103.

5. Van der Veer.A. The Asthma problem. N. Y. Med .J. 1920;112:392-399.

6. Young jinAhn, Soo-Youn An, Tae-Bin Won, Jeong-Whun Kim, Chul Hee Lee, Yang-Gi Min et al. Nasal polyps: An independent risk factor for bronchial hyperresponsiveness in patients with allergic rhinitis. 2Am J Rhinol Allergy 2010;24:359-363.

7. Gillian Dunlop, Glenis K Scadding, and Valerie J. Lund. The Effect of Endoscopic Sinus Surgery on Asthma: Management of Patients With Chronic Rhinosinusitis, Nasal Polyposis, and Asthma. American Journal of Rhinology.July-August 1999, Vol. 13, NO.4.

8. Marleen Vleming, Anton E. Stoop, Rene J. Middelweerd, and Nico de Vries Results of Endoscopic Sinus Surgery for Nasal Polyps. American Journal of Rhinology 5:173-176,1991

9. M.R. Miller, J. Hankinson, V. Brusasco, F. Burgos, R. Casaburi, A. Coates et al. Standardisation of spirometry. EurRespir J 2005; 26: 319-338

10. Global Initiative for Chronic Obstructive Lung Disease. Spirometry for health care providers.(Updated 2010). Available at https://www.google.com/url?sa=t\&rct=j\& $\mathrm{q}=\&$ esrc $=$ s\&source $=$ web $\& \mathrm{~cd}=3 \& \mathrm{cad}=\mathrm{rja}$ \&uact $=8 \&$ ved $=2$ ahUKEwjL7ZLy9NzjAh Ul6nMBHdivB7cQFjACegQIAhAC\&url= https\%3A\%2F\%2Fgoldcopd.org\%2Fwpcontent $\% 2$ Fuploads $\% 2 \mathrm{~F} 2016 \% 2 \mathrm{~F} 04 \% 2 \mathrm{~F}$ GOLD_Spirometry_2010.pdf\&usg=AOvV aw0yOPN0N01fSjfmSLTB_6IY

11. Harpreet Ranu, Michael Wilde, Brendan Madden. Pulmonary Function Tests. Ulster Med J 2011;80(2):84-90

12. North West ENT \& Allergy "Total Nasal Symptom Score" Portland accessed on 1102-2019. Available at

13. https://www.google.com/url?sa=t\&rct=j\& $\mathrm{q}=\& \mathrm{esrc}=\mathrm{s} \&$ source $=$ web $\& \mathrm{~cd}=3 \& \mathrm{cad}=\mathrm{rja}$ \&uact $=8 \&$ ved $=2$ ahUKEwil8Nve9tzjAhX B4nMBHUlqCtMQFjACegQIBBAC\&url $=$ https $\% 3 \mathrm{~A} \% 2 \mathrm{~F} \% 2 \mathrm{Fwww}$.nwentallergy.co m\%2Fdocs\%2FTotal_Nasal_Symptom_Sc ore.pdf\&usg=AOvVaw3IdzSjRRL14lFg4j04553 
14. Sridevi Karuthedath, Ishwar Singh, Shelly Chadha, Impact of Functional Endoscopic Sinus Surgery on the Pulmonary Function of Patients with Chronic Rhinosinusitis: A Prospective Study Indian J Otolaryngol Head Neck Surg (Oct-Dec 2014) 66(4):441-448.

15. Alexander J. Osborn, MD, PhD; Randy Leung, MD; Felix Ratjen, MD; Adrian L. James, MA, DM "Effect of Endoscopic Sinus Surgery on Pulmonary Function and Microbial Pathogens in a Pediatric Population With Cystic Fibrosis" Arch Otolaryngol Head Neck Surg. 2011;137(6):542-547.

16. Ahmed M. Youssef, MD1, Osama G. Abdel-Naby Awad, MD, Mohamed Taha, MD, "Pulmonary Function of Patients with Chronic Rhinosinusitis and the Impact of Endoscopic Sinus Surgery" Egypt J Otolaryngol 2018;34:167-72

17. Slavin RG. Sinus disease and asthma. Ear Nose Throat J. 1984 Feb;63(2):45, 49-50, 53-4.

18. Liao H, Shen Y, Wang P. "Clinical analysis of nasal resistance and pulmonary function testing in patients with chronic nasal-sinusitis and nasal polyps" Journal of clinicalotorhinolaryngology, head, and neck surgery, 2015 May;29(9):784-7, 799.

19. Pan S, He H, Guan B, Liu T, Yuan X, Ma $\mathrm{W}$ and Xie Y: The effect of endoscopic sinus surgery on pulmonary function of chronic rhinosinusitis patients with asthma. Lin Chung Er Bi Yan HouTou Jing WaiKe ZaZhi. 28:1118-1121. 2014. PubMed/NCBI
20. Pete S. Batra MD, Robert C. Kern MD, Anju Tripathi MD , David B. Conley MD , A. M. Ditto MD , G. K. Haines III MD, et al, "Outcome analysis of endoscopic sinus surgery in patients with nasal polyps and Asthma" The Laryngoscope 03 September 2010 / Volume 113, Issue 10, Pages 17031706. 